\title{
Perspectivas do EAD e do teletrabalho na melhoria da mobilidade urbana da Região Metropolitana de São Paulo (RMSP).
}

E-learning and teleworking perspectives on improving urban mobility in the Metropolitan Region of São Paulo (MRSP).

Perspectivas de la EaD y del teletrabajo en la mejoría de la movilidad urbana en la Región Metropolitana de São Paulo (RMSP).

\section{Roberta Betania Ferreira Squaiella}

Doutoranda, Universidade Presbiteriana Mackenzie, Brasil. robssquaiella@gmail.com.br

Maria Victoria Marchelli Mestre, Universidade Presbiteriana Mackenzie, Brasil. victoria.marchelli@gmail.com

Roberto Righi Professor Doutor, Universidade Presbiteriana Mackenzie, Brasil. roberto.righi@mackenzie.br 


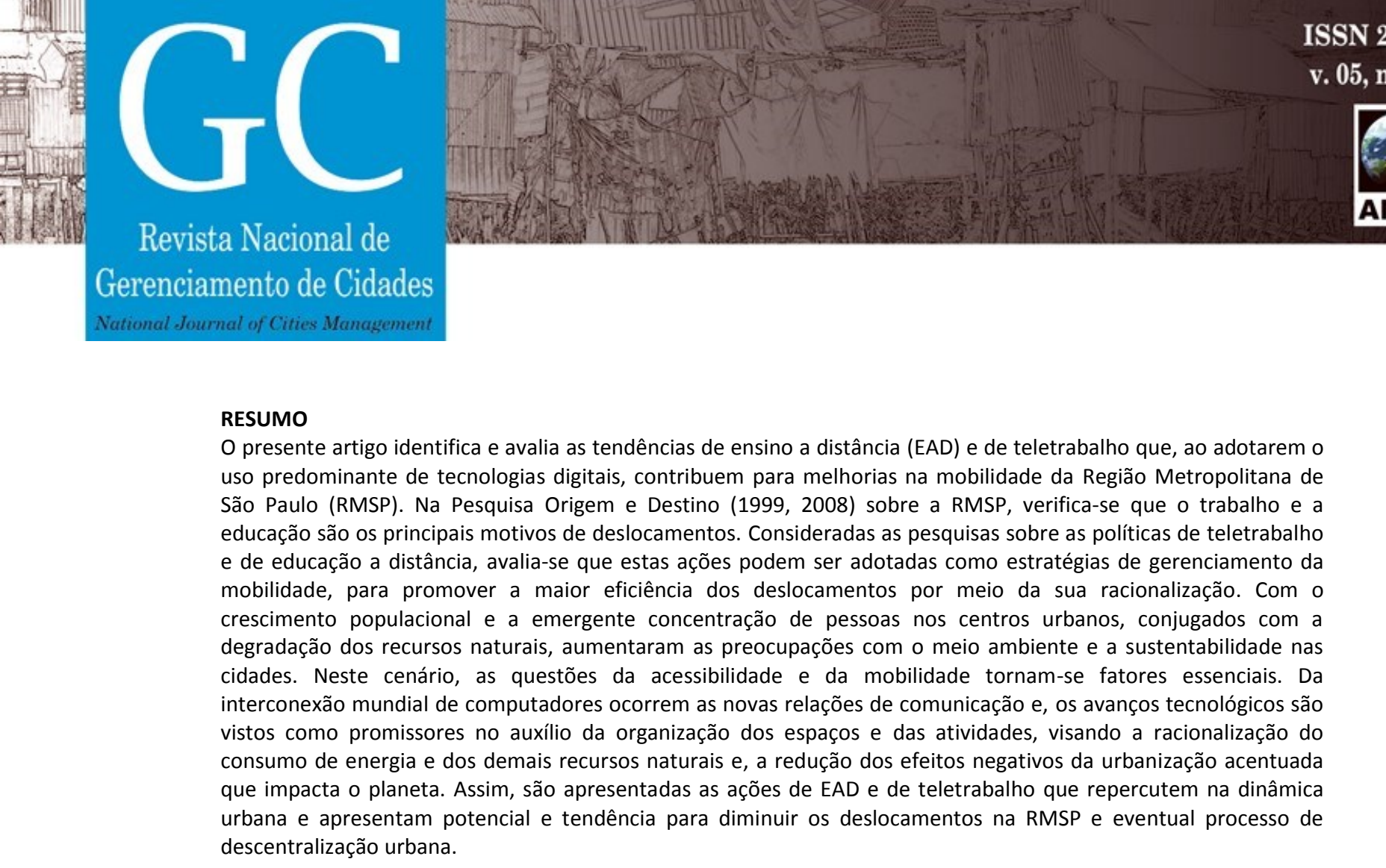

PALAVRAS-CHAVE: Mobilidade. Teletrabalho. Educação a distância.

\section{ABSTRACT}

The present article identify and evaluate the distance learning (e-learning) and teleworking trends that, by adopting the predominant use of digital technologies, contribute to improvements in the mobility of the Metropolitan Region of São Paulo (RMSP). In the Origin and Destination Research $(1999,2008)$ on the RMSP, it is verified that work and education are the main reasons for displacements. Considering researches on teleworking and distance learning policies, it is evaluated that these actions can be adopted as mobility management strategies, to promote the greater efficiency of the displacements through their rationalization. With the population growth and the emerging concentration of people in urban centers coupled with the degradation of natural resources, concerns about the environment and sustainability in cities have increased. In this scenario, issues of accessibility and mobility become essential factors. From the global interconnection of computers occur the new communication relations, and technological advances are seen as promising in the organization of spaces and activities, aiming at rationalizing energy consumption and other natural resources, and reducing the negative effects of accentuated urbanization that impacts the planet. Thus, the actions of e-learning and teleworking are presented, which have repercussions on the urban dynamics and present potential and tendency to reduce the displacements in the RMSP and eventual urban decentralization process.

KEYWORDS: Mobility. Teleworking. Distance Learning.

\section{RESUMÉN}

Este artículo busca identificar y evaluar las tendencias de educación a distancia (EaD) y teletrabajo que, al adoptar el uso predominante de las tecnologías digitales, contribuyen en mejorías en la movilidad de la Región Metropolitana de São Paulo (RMSP). En la Búsqueda de Origen y de Destino $(1999,2008)$ sobre la RMSP, se verifica que el trabajo y la educación son los principales motivos de los desplazamientos. Teniendo en cuenta las investigaciones sobre las políticas de teletrabajo y educación a distancia, se evalúa que estas acciones pueden ser tomadas como estrategias de gestión de movilidad, para promover una mayor eficiencia de desplazamientos mediante su racionalización. Con el crecimiento demográfico y la emergente concentración de personas en los centros urbanos, conjugado con la degradación de los recursos naturales, aumentaron las preocupaciones por el medio ambiente y la sostenibilidad en las ciudades. En este escenario, los problemas de accesibilidad y movilidad son factores esenciales. De la interconexión global de ordenadores se producen nuevas relaciones de comunicación y, los avances tecnológicos son vistos como promisores en el auxilio de la organización de los espacios y actividades, buscando racionalizar el consumo de energía y otros recursos naturales, y la reducción de los efectos negativos de la urbanización acentuada que impacta el planeta. Así, se presentan las acciones de educación a distancia y teletrabajo que inciden en la dinámica urbana y tienen potencial y tendencia para disminuir el desplazamiento en el RMSP y eventual proceso de descentralización urbana. 
PALABRAS CLAVE: Movilidad. Teletrabajo. Educación a distancia. INTRODUÇÃO

Com base na Pesquisa Origem e Destino (OD), da Companhia Metropolitana de São Paulo (METRO, 2008), verifica-se que o trabalho e a educação, juntos, representam quase $80 \%$ dos deslocamentos na Região Metropolitana de São Paulo (RMSP). Assim, são destacadas as políticas de teletrabalho e de educação a distância, que atualmente apresentam soluções realizadas prioritariamente pela iniciativa privada e, que trazem impactos positivos para as cidades, pois contribuem para a redução de deslocamentos das pessoas. Compreendendo-se que a falta de mobilidade urbana pode gerar impactos ruins tanto para a qualidade de vida, quanto para as questões econômicas das cidades, avalia-se que estas medidas trazem novos hábitos, que tem potencial de auxiliar na articulação da mobilidade.

Para enfrentar os desafios e o impacto do crescimento urbano acelerado, foi criado o conceito de cidades inteligentes (em inglês, Smart City) que, apoiado nas redes de comunicação de massa, visa uma nova abordagem para ajudar a solucionar os problemas dos grandes centros urbanos, por meio de um processo de compartilhamento de informações na sua construção e no seu desenvolvimento, de maneira mais sustentável. Entende-se que o conceito de cidades inteligentes está apoiado no uso de tecnologias digitais na gestão das cidades, o que precisa de adaptação das grandes metrópoles para solucionar os problemas e adequar a sua infraestrutura (ANDRADE e GALVÃO, 2016). Porém, este artigo pretende evidenciar as ações que são impactadas pelo uso das tecnologias e que afetam a mobilidade urbana, independentemente de políticas de gestão urbana.

A dinâmica da vida resultante do processo econômico contemporâneo leva a uma grande concentração populacional nas cidades, em busca de trabalho, de educação, de cultura, de saúde e de lazer. De acordo com os dados do IBGE, 84,36\% dos brasileiros vivem em cidades (IBGE, 2014), porém observa-se que a maior parte delas, especialmente as maiores, não estão estruturadas para receber este fluxo demográfico, o que resulta na não solução daquelas expectativas, agravadas por problemas como a falta de moradia, de empregos, de infraestrutura básica e de condições adequadas para a mobilidade urbana. Sem uma mudança consistente e a falta da implantação de soluções adequadas, esta realidade tende a se agravar, pois de acordo com a Organização das Nações Unidas (ONU, 2007), atualmente 50\% da população mundial vive em áreas urbanas e, a previsão é de que em 2030 esta proporção seja de aproximadamente $60 \%$ da população mundial (ONU, 2012).

Para equalizar a demanda de infraestrutura urbana esta deve estar condizente com o crescimento da cidade. Quando a infraestrutura urbana não acompanha o crescimento desordenado da cidade, aumentam os assentamentos subnormais, além do pouco acesso aos serviços de saúde, de educação e de mobilidade urbana. Esta última questão pode ser um fator determinante no crescimento desordenado, pois devido aos altos valores das moradias próximas aos centros urbanos, a população habita regiões cada vez mais distantes dos 
mesmos, o que gera a necessidade de criação de infraestruturas nas áreas mais periféricas (ANDRADE e GALVÃO, 2016). Porém, devido ao alto custo da infraestrutura urbana, entendese que o adensamento populacional é um caminho que possibilita que os custos da organização possam ser socializados. Acredita-se que a maior parte da população deverá viver de forma concentrada, sob altas ou médias densidades, para que ela possa se apresentar de maneira sustentável. Já a baixa densidade de ocupação do território só é possível em sociedades que possuem alto poder aquisitivo, o que limita a socialização dos recursos (MARCHELLI et al., 2015).

Dentro deste cenário, um ordenamento urbano adequado, que apresente soluções mais inteligentes e humanas, é um grande desafio para grande parte das cidades, que devem atender não apenas as atuais demandas da sociedade, mas também que possam atender as futuras demandas em ascensão. Atualmente, com o grande desenvolvimento das tecnologias da informação e comunicação, a sociedade ampliou as formas de comunicação e mobilidade, tanto no âmbito físico, com os transportes, quanto no virtual, com os meios de comunicação de massa (MARCHELLI et al., 2015). Como o arquiteto e urbanista Vishaan Chakrabarti (2013) expôs no seu livro A country of cities: A manifesto for an Urban America, as cidades precisam se organizar dentro do seu tecido urbano, a partir de um adensamento adequado para garantir uma melhor mobilidade, usufruir de menor espaço físico e proporcionar maior sustentabilidade, buscando, assim, uma melhor qualidade de vida para seus habitantes. A tecnologia, por sua vez, ao ultrapassar os limites físicos, permite menor ocupação do espaço físico e uma nova configuração urbana se descreve a partir dela.

\section{MOBILIDADE URBANA}

Desde os primórdios da civilização, as cidades se consolidaram como centros de convivência da humanidade, onde ocorrem as manifestações de interesse e das inter-relações coletivas, para as construções sociais, as disputas e a observação da história comunitária (MATTA, 2002). Com o grande crescimento da população urbana, a partir do século $X X$, novas centralidades e suburbanizações foram formadas nas metrópoles contemporâneas, em contraposição às cidades tradicionais, que possuíam uma estrutura monocêntrica, com polarização e concentração das funções urbanas pelo núcleo central. As centralidades de uma estrutura policêntrica, decorrentes da descentralização de empregos, de educação, de moradias, de comércios e de outras funções, são resultantes das iniciativas privadas, das políticas públicas, do desenvolvimento dos transportes e das comunicações (MARCHELLI et al., 2015).

As cidades evoluem de acordo com as mudanças técnicas e sociais da sociedade. A interferência das tecnologias da informação e comunicação ocorre na reconfiguração dos espaços urbanos e das práticas sociais, regidos pelo tempo real e imediato no mundo global. 
Novos estilos de vida e funções cada vez mais ligadas às redes telemáticas, emergem numa maior velocidade.

De acordo com a pesquisa da agência de comunicação empresarial Central Press (MAIS, 2015), a mobilidade urbana é uma das grandes questões de discussão nas grandes capitais de todo o mundo. Nos maiores eventos sobre inovações, são discutidas soluções que possam auxiliar na questão da mobilidade, sendo que alguns especialistas, como o André Telles (apud MAIS, 2015), acreditam que a economia colaborativa tende a mudar a realidade do trânsito nas grandes cidades. Com a grande inserção dos recursos tecnológicos é possível compartilhar os meios de transporte, como carros e bicicletas, além de inserir soluções inteligentes, como sinais de trânsito que são sincronizados em tempo real, de acordo com o tráfego.

O conceito de compartilhamento, que ressalta o senso de comunidade e resgata práticas sociais cooperativas, permite o uso de bens, espaços e serviços de forma coletiva, como o uso compartilhado de espaços de trabalho, de transporte e de veículos alternativos. Assim, o uso das tecnologias digitais possibilita facilidades na mobilidade urbana como: redução do tempo gasto em grandes congestionamentos, redução das grandes distâncias entre a moradia e o trabalho, e a racionalização de despesas e de consumo (SANTOS, 2014). Além disso, possibilita a redução da necessidade de viagens para os motivos de educação e trabalho, que representam os maiores fatores de deslocamento nas Regiões Metropolitanas brasileiras.

A tecnologia evolui em grande velocidade e tem se tornado presente na vida da maioria das pessoas. Seu uso tem sido benéfico para muitos, permitindo superar grandes distâncias a partir de um ambiente virtual. A sua contribuição na diminuição de deslocamentos é de fato importante para a vida urbana. Porém, deve existir um equilíbrio entre a tecnologia e a cidade, pois apesar da alta capacidade de expansão das redes de informação e comunicação, que possibilita a descentralização das atividades, as cidades precisam cada vez mais das suas centralidades para atingir a sustentabilidade urbana. Assim, cidades e tecnologias são elementos que precisam se articular de modo a garantir qualidade de vida para as atuais e as futuras gerações da sociedade.

\section{Região Metropolitana de São Paulo}

A conurbação das cidades que constituem as Regiões Metropolitanas ocasiona uma mescla da paisagem urbana, bem como dos serviços que vão além dos limites municipais. Na figura 1 , a imagem de satélite registra a expansão da conurbação na Região Metropolitana de São Paulo, entre os anos de 1986 e 2014. Com a grande quantidade de pessoas que circulam diariamente entre as divisas dos municípios, é um grande desafio equacionar as diferentes gestões entre eles. Para isto, é necessário um planejamento para o desenvolvimento urbano integrado, que vise conter o espraiamento urbano e os grandes deslocamentos, para se ter acesso aos serviços e às oportunidades que normalmente se concentram nos centros. As ações tornam-se mais eficientes quando as interconexões metropolitanas, o planejamento e a gestão dos 
cada dez anos. Assim, no presente artigo é utilizada a última pesquisa OD, publicada em 2008, com os dados referentes ao ano de 2007, comparados ao ano de 1997. Com esta ressalva, verifica-se na figura 3 que, em 1997 e em 2007, o trabalho e a educação foram, respectivamente, o primeiro e o segundo motivo de viagens na RMSP, considerando-se a seguinte ordem decrescente de importância, em 2007: trabalho, 44\%; educação, 35\%; outros motivos referentes a assuntos pessoais, $9 \%$; lazer, $4 \%$; saúde, $4 \%$ e compras, $4 \%$. Ressalta-se que esses dois motivos (trabalho e educação), juntos, representam quase $80 \%$ dos deslocamentos na RMSP. Além disto, há clara tendência de aumento da participação destes dois componentes nos últimos levantamentos, mostrando a importância do tema deste estudo.

Figura 3: Região Metropolitana de São Paulo: Total de viagens diárias por motivo, 1997 e 2007.

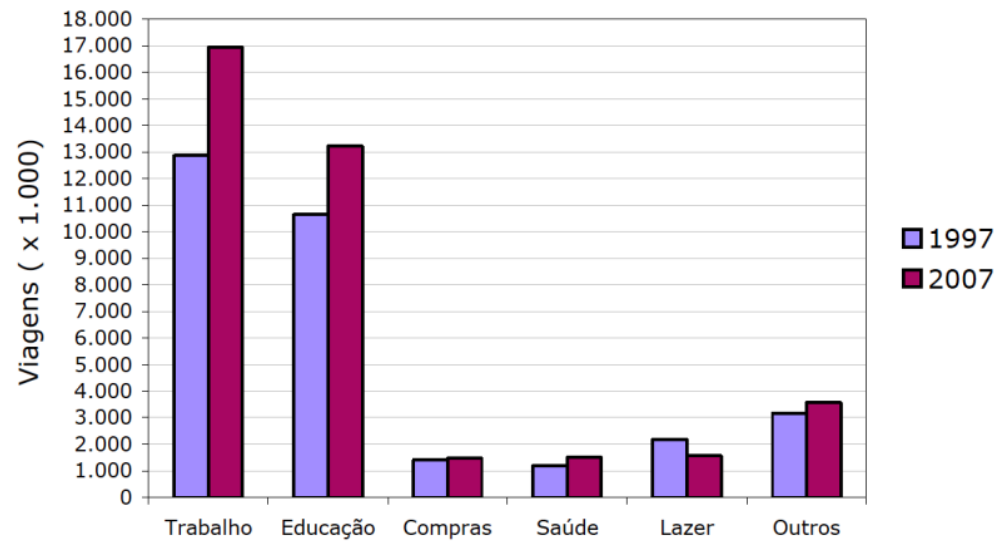

Fonte: METRO, 2008, p.47.

De acordo com o suplemento Acesso à Internet e à Televisão e Posse de Telefone Móvel Celular para Uso Pessoal, da Pesquisa Nacional por Amostra de Domicílios - PNAD 2015, realizado pelo IBGE (IBGE, 2016), observa-se o uso das tecnologias móveis para o acesso à internet no Brasil. Em 74\% dos domicílios da RMSP, são utilizados os serviços de internet, o que supera a média nacional de 57,8\%. Destaca-se que, destes domicílios na RMSP, 79,8\% utilizam a internet por meio de microcomputador, $92,1 \%$ por meio de telefone móvel e, apenas $29,1 \%$ por meio de tablet (IBGE, 2016). Esses dados demonstram a grande demanda de domicílios que estão equipados com dispositivos eletrônicos para o acesso à internet.

Com relação à educação, destaca-se que, em 2015, dos 102,1 milhões de usuários de internet no Brasil, aproximadamente 29 milhões $(28,4 \%)$ eram estudantes. Observa-se que o uso da internet é proporcionalmente maior entre os alunos de instituições de ensino privadas, com $97,3 \%$ dos alunos (9,0 milhões), enquanto esta proporção cai para $73,7 \%$ (19,9 milhões) dos alunos das instituições públicas (IBGE, 2016). Com relação às atividades de trabalho, a SAP Consultoria aponta que, em pesquisa nacional, os notebooks e os telefones móveis são os equipamentos mais utilizados pelas pessoas que trabalham em sua residência. Isso vai de 
encontro às políticas de "traga o seu próprio dispositivo" (em inglês, bring your own device), que é uma tendência mundial de incentivo aos trabalhadores a utilizarem os próprios dispositivos pessoais para desempenharem suas atividades profissionais (TREVISAN et al., 2016). Essa tendência também está sendo adotada em instituições de ensino, para que o aluno estude com o seu próprio dispositivo, dentro ou fora da instituição, promovendo, dentre outras questões, a personalização no acesso aos dispositivos eletrônicos.

\section{Trabalho e mobilidade}

Por muito tempo, a construção de infraestrutura urbana ou de hardware, para o aumento da capacidade viária, foi a solução adotada por centenas de cidades, para solucionar os problemas da mobilidade urbana. Porém, o aumento da malha viária acabou resultando no incentivo à motorização e à maior dependência do automóvel. $O$ impacto disso para as cidades é negativo, pois acarreta no aumento dos congestionamentos, que ocasionam os seguintes problemas: emissões de carbono, poluição do ar e acidentes de trânsito. Além disso, o uso massivo do automóvel contribui para a segregação de comunidades e, os custos decorrentes destes problemas podem atingir até $10 \%$ do PIB das cidades, o que afeta o poder público, as pessoas e o setor corporativo (EMBARQ, 2015). Mais recentemente houve grandes investimentos no transporte público, que também é muito dispendioso e impactante para o meio ambiente. É tempo de pensar nas tecnologias de softwares, de baixo impacto e elevada eficiência.

Nas grandes cidades brasileiras, o trabalho é o principal motivo de deslocamentos e chega a representar, aproximadamente, a metade das viagens realizadas diariamente. Desta forma, observa-se que as corporações têm um papel importante na solução dos problemas de mobilidade. Os horários coincidentes de início e de término do expediente de trabalho e, a maioria dos automóveis estar ocupada por apenas uma pessoa, são fatores agravantes, pois além de gerarem grandes congestionamentos, necessitam de maior oferta de vagas de estacionamento, o que provoca um alto custo de construção e manutenção deste espaço. Os impactos ambientais também são fatores a serem destacados, pois $47 \%$ das emissões de CO2 do setor de energia brasileira são provenientes do transporte (EMBARQ, 2015).

Atualmente, tem se tornado uma tendência mundial a construção de um plano de mobilidade corporativa, que visa introduzir políticas de Gestão da Demanda de Viagens (GDV, do inglês Transport Demand Management, TDM) na cultura das instituições. A intenção é racionalizar o uso do automóvel, beneficiando os funcionários, a cidade e as próprias organizações. Para isso, as organizações devem estimular a mudança de hábitos de deslocamento, por meio de informações e incentivos para o uso de meios de transporte mais sustentáveis e eficientes em relação ao automóvel (EMBARQ, 2015).

A revolução tecnológica que está transformando a maneira como as pessoas vivem, aprendem e trabalham, supera a visão do passado do planejamento urbano autoritário e estatal. Isso tem impactado nas dimensões da vida profissional e nas questões da mobilidade urbana. As 
inovações tecnológicas e as tendências globais impulsionam a criação de novos modelos de negócios, que buscam propiciar melhor produtividade no trabalho por meio de um equilíbrio entre vida pessoal e profissional. Neste contexto, o teletrabalho é visto como uma alternativa potencial para a operacionalização desse cenário e, resulta em melhorias nas questões de mobilidade nos grandes centros urbanos.

Conforme já analisado, sendo o trabalho o principal motivo de deslocamentos na RMSP, algumas empresas buscam adotar algumas práticas para contribuir com a mobilidade na cidade. Por exemplo, a agência Central Press afirma que algumas medidas estão sendo tomadas para contribuir com a melhoria da mobilidade, como o incentivo à implantação de horários alternativos para a entrada e a saída dos funcionários nas empresas (MAIS, 2015). Isso favorece a redução dos horários de grande concentração de trânsito, porém ainda mantém a grande circulação de carros nas vias. Outras medidas adotadas são as práticas de trabalho remoto, que possibilitam ao funcionário realizar as suas atividades a distância, em período integral ou parcial. Por meio de uma infraestrutura tecnológica, os funcionários podem realizar o trabalho de sua residência, no campo de trabalho ou em centros satélites, descentralizados da sede principal da empresa (SAP, 2015).

De acordo com Boek (2016), muitas empresas estão aderindo ao teletrabalho como alternativa para determinados cargos. Isso impacta em toda a estrutura econômica do trabalho, com economias para a empresa, para o funcionário e para a cidade. Para o funcionário, é possível destacar como principais benefícios: menor necessidade de deslocamento entre casa e trabalho; flexibilização da carga horária e do ambiente de trabalho; e, o aumento da produtividade, pois economiza-se o tempo do deslocamento. Para a empresa, é possível destacar aumento da produtividade e economia na manutenção do espaço físico. Também, esta estratégia tem muito haver com as novas tendências de flexibilização e terceirização do trabalho. Para a cidade, há economia devido aos seguintes fatores: redução dos investimentos em infraestrutura viária e de transportes, diminuição na queima de combustíveis e emissão de gases poluentes pelos automóveis; menor proporção de acidentes no trânsito e da manutenção das vias públicas e, diminuição da necessidade na mobilidade urbana (SAP, 2015). De acordo com Belda (2010), o estudo patrocinado pela Global Enviroment, em 2006, por meio do Banco Mundial, já apontava o teletrabalho como uma medida de gestão da mobilidade na cidade de São Paulo. Esse autor também aponta que, em 2008, uma reportagem no jornal $O$ Estado de São Paulo, indicava como início da adoção de teletrabalho no Brasil, as relações de trabalho em empresas multinacionais, que parcial ou integralmente abrangiam $23 \%$ dos empregados do setor privado.

O Censo Demográfico 2010, aponta que, do total de 86 milhões de trabalhadores brasileiros, em 2010, 87,1\% trabalhavam no mesmo município onde moravam, sendo que 20 milhões $(23,2 \%)$ trabalhavam no próprio domicílio (IGBE, 2011). Considerando-se esses dados, a SAP Consultoria em RH realizou a pesquisa Home Office Brasil 2016, que contou com a participação de 325 empresas de diferentes segmentos e portes, de diversas regiões do país, e observou-se 

Assim, observa-se que quanto maior o nível de ensino, maior é a centralidade das instituições nos centros urbanos. Dentre as funções destinadas às cidades, como a administração econômica e política, Matta (2002) destaca que a reprodução e a produção do conhecimento passaram a ser um dos serviços e uma das funções mais importantes das cidades. Isso contribuiu para o desenvolvimento das escolas e da educação presencial, pois a posição de convivência e decisões só era tida como possível no meio urbano. Apenas no final do século $X X$, com o surgimento da sociedade informatizada foi possível construir um convívio em centros virtuais e ambientes eletrônicos, que criaram comunidades trans-urbanas (MATTA, 2002). Nesse cenário, a educação a distância (EAD) surge como opção de formação, produção e reprodução de conhecimento trans-urbano, atuando de maneira ativa no processo de transformação da sociedade atual. Os efeitos decorrentes do crescimento da EAD podem influenciar positivamente a mobilidade na estrutura urbana.

Matta (2002) ressalta que a emergência das tecnologias e técnicas de comunicação estão possibilitando novas formas alternativas de construção e debate social, capazes de gerar diferentes ambientes de construção social supraurbanas e supralocais, mesmo que continuem influentes em cada localidade. A sociedade em rede consegue produzir o debate urbano necessário para a construção social, o que torna possível a trans-urbanidade, "formada por comunidades compostas por identidades não territoriais, que permitem o debate e as construções sociais em outros níveis" (MATTA, 2002, p.3).

Para Stravos Xanthpoylos (apud PIRES, 2015), um dos principais atrativos do curso a distância, principalmente no nível de pós-graduação, é a questão da mobilidade. O perfil atual de estudante e trabalhador necessita de maior flexibilidade para os estudos. Nos grandes centros urbanos, o deslocamento do trabalho para a instituição de ensino pode representar um grande fator de desmotivação para os estudos, enquanto que o ensino a distância possibilita a flexibilidade necessária. $\mathrm{O}$ aluno não precisa sair mais cedo do trabalho para conseguir chegar na instituição. Ele pode estudar de qualquer lugar, até mesmo no seu local trabalho.

Somado a tudo isto, as instituições de ensino investem em tecnologias de ensino a distância que possibilitam aos alunos reduzirem a sua frequência nas instituições para cada 15 dias. Apesar de ainda não se identificarem pesquisas específicas para a RMSP, observa-se que, em Curitiba, a Universidade Positivo já realizou estudos e, de acordo com Carlos Longo (apud MAIS, 2015), a previsão é que a maior implantação de cursos a distância possa reduzir $6 \%$ do trânsito em horários de pico, ao redor desta universidade. Isto representa uma redução de aproximadamente 10.000 carros em circulação durante os 14 dias de aulas on-line.

Na RMSP é possível prever o impacto dos cursos a distância, avaliando os dados a seguir, sobre as instituições de ensino superior. Em 2014, haviam 941.144 alunos matriculados em cursos presenciais, em 232 instituições de ensino. Isso representou 54,6\% do total das matrículas no Estado de São Paulo (1,72 milhão). Observa-se que 833.461 matrículas são referentes aos cursos em instituições da rede privada e 107.683, da rede pública. Além dos cursos 
presenciais, a RMSP também concentrou o maior número de alunos em cursos a distância, com 102.476 matrículas, sendo 101.389 na rede pública e, 1.087 na rede privada (CAPELATO et al., 2016). Verifica-se assim, que os cursos a distância já representam aproximadamente $10 \%$ do total de alunos matriculados no nível superior, na RMSP, e a tendência é que esta proporção aumente rapidamente nos próximos anos. De acordo com os dados do Censo da Educação Superior 2015, a nível nacional, as matrículas dos cursos a distância representaram $17,8 \%$ do total de matrículas no nível superior (MEC/INEP, 2016). Considerando-se a projeção de crescimento da EAD nos últimos cinco anos, conforme os dados deste Censo, estima-se que o número de alunos em cursos a distância deve superar o ensino presencial daqui a seis anos (KOIKE, 2017).

Além desta estimativa, ressalta-se que o governo tem ampliado o número de aprovações para novos polos de apoio presencial ao aluno (KOIKE, 2017). Esses polos de apoio são exigências legais, para que a instituição ofereça um local físico para o atendimento presencial ao aluno, e descentralizam as atividades pedagógicas das instituições, possibilitando que um maior número de pessoas tenha acesso ao ensino superior. Esses locais geralmente contam com uma infraestrutura escolar reduzida, dentro de instituições de ensino já existentes para o ensino fundamental e nível médio. Assim, otimizando a infraestrutura escolar já existente para os níveis mais básicos, em regiões descentralizadas, os cursos a distância podem representar a única oportunidade de estudos, em nível superior, principalmente para as pessoas de baixa renda e que moram longe dos grandes centros urbanos (SQUAIELLA, 2016).

\section{CONCLUSÕES}

A interferência das tecnologias da informação e comunicação na sociedade contemporânea deve atingir, de forma cada vez mais intensa, o desenvolvimento das cidades. Os recursos informatizados podem trazer melhorias para o espaço urbano, principalmente na mobilidade urbana, com o compartilhamento de informações, possível em uma sociedade mais equipada e consequentemente mais conectada, ativa e participativa. Atualmente, há uma clara tendência pela Internet móvel, acessada por equipamentos como os smartphones.

A interferência das tecnologias impacta em mudanças no uso dos bens, dos serviços e na mobilidade urbana, visto que a utilização do ciberespaço propicia o compartilhamento de dados e informações que contribuem para a economia de energia e a preservação dos recursos naturais. A mobilidade urbana, para tornar-se sustentável, deve ser desregulamentada progressivamente de forma a potencializar as tecnologias referidas, conjugando o privado, mantendo os interesses públicos, de maneira a permitir melhores deslocamentos, com menores impactos ambientais.

Acredita-se que deve ocorrer um equilíbrio entre a configuração urbana e as tecnologias disponíveis. Ainda que as tecnologias permitam uma descentralização, não se pode pensar apenas dessa maneira. As cidades precisam cada vez mais de um adensamento, para melhorar 
a mobilidade e a qualidade urbana. A tecnologia, por sua vez, permite intensificar as conexões, tornando as comunicações mais eficientes e garantindo uma série de benefícios que foram expostos ao longo deste artigo. As tecnologias constituem uma tendência que não mudará, ao contrário, elas têm um importante papel e continuam ganhando novas dimensões, sendo que o uso das mesmas precisa ser adotado com o objetivo de melhorar e permitir maior eficiência urbana.

Considerando-se o longo caminho da gestão pública para tornar as cidades brasileiras em cidades inteligentes, acredita-se em soluções da iniciativa privada que contribuem para o desenvolvimento inteligente da cidade, com melhorias na mobilidade urbana e na qualidade de vida de seus cidadãos. Desta forma, destaca-se a inserção das tecnologias para as ações remotas no trabalho e na educação, que juntos representam os maiores motivos de deslocamentos na Região Metropolitana de São Paulo. A educação a distância e o teletrabalho são alternativas viáveis e potenciais para a redução de deslocamentos e, consequentemente, apresenta contribuições para melhoria dos impactos prejudiciais na mobilidade urbana.

\section{REFERÊNCIAS BIBLIOGRÁFICAS}

ANDRADE, Josiane Nascimento; GALVÃO, Diogo Cavalcanti. O conceito de smart cities aliado à mobilidade urbana. REVISTA HUM@NAE, v. 10, n. 1, 2016.

BELDA, Rogerio. Teletrabalho em São Paulo, desconhecido, porém presente. Revista dos transportes públicos-antpano 33, 2010.

BOECK, Aloha. Aumenta o número de empresas que adotam o home office como prática no Brasil. The City Fix Brasil. 11 nov. 2016.

CAPELATO, Rodrigo et. al. Mapa do ensino superior no Brasil 2016. SEMESP, São Paulo, 2016.

CHAKRABARTI, Vishaan. A country of cities: a manifesto for an urban America. Metropolis Books, 2013.

CPTM. A Companhia. On-line. 2016. Disponível em: <http://www.cptm.sp.gov.br/a-companhia/Pages/acompanhia.aspx>. Acesso em 28 fev. 2017.

DENATRAN. Frota de veículos - 2016. Frota por município e tipo - outubro 2016. 2016.

EMBARQ. Passo a passo para a construção de um plano de mobilidade corporativa. Embarq Brasil, set. 2015

EMPLASA. Sobre a RMSP. On-line. 2016. Disponível em: <https://www.emplasa.sp.gov.br/RMSP>. Acesso em 28 fev. 2017.

IBGE, Instituto Brasileiro de Geografia e Estatística. Censo Demográfico 2010 - Educação e Deslocamento. Rio de Janeiro: IBGE, 2012.

IBGE, Instituto Brasileiro de Geografia e Estatística. Perfil dos municípios brasileiros 2013. Rio de Janeiro: IBGE, 2014.

IBGE, Instituto Brasileiro de Geografia e Estatística. PNAD 2015 - Acesso à Internet e à Televisão e Posse de Telefone Móvel Celular Para Uso Pessoal. Rio de Janeiro: IBGE, 2016. 


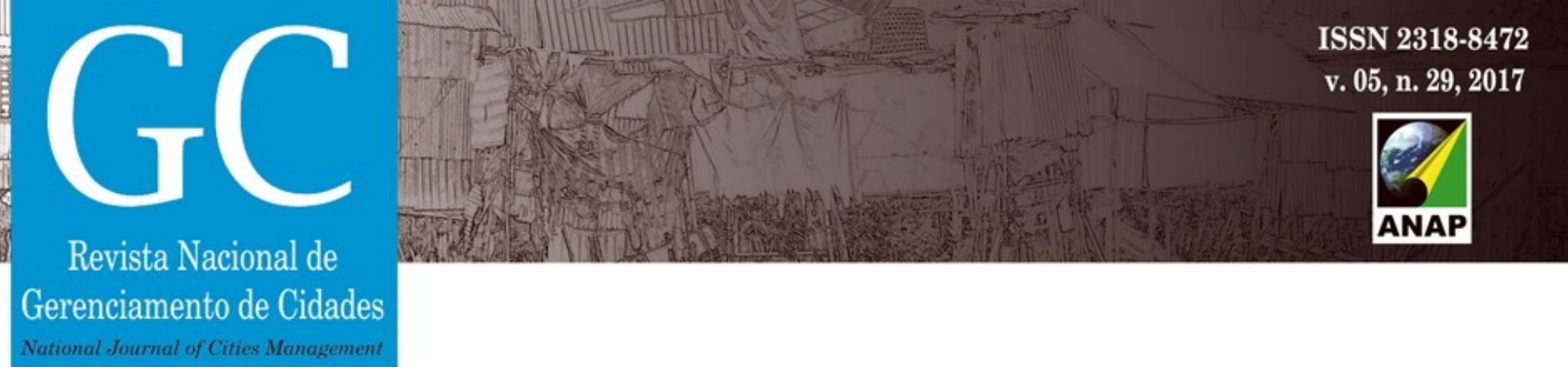

KOIKE, Beth. Número de alunos em cursos a distância representará 51\% 9,2 milhões de matriculados. Valor. São Paulo, 17 fev. 2017.

MEC/INEP, Ministério da Educação e Instituto de Estudos e Pesquisas Educacionais Anísio Teixeira. Censo da Educação Superior 2015. Brasília: governo federal, 2016.

MAIS aulas pela internet e menos carros nas ruas. Central Press. 14 out. 2015. On-line. Disponível em: <http://www.centralpress.com.br/mais-aulas-pela-internet-e-menos-carros-nas-ruas/?print=1>. Acesso em 16 out. 2015.

MARCHELLI, M. Victoria; SQUAIELLA, Roberta B. F.; RIGHI, Roberto. O papel do ciberespaço e das novas tecnologias da informação e da comunicação na melhoria da sustentabilidade do habitat urbano. In: $3^{\circ} \mathrm{CIHEL}$ - Congresso Internacional da Habitação no Espaço Lusófono. São Paulo: FAU USP, 2015.

MATTA, Alfredo E. Rodrigues. A Educação a Distância e as Trans-urbanidades. In: SEMINÁRIO NACIONAL ABED DE EDUCAÇÃO A DISTÂNCIA, n.1, Belo Horizonte/MG, 2002.

METRÔ, Companhia do Metropolitano de São Paulo. Pesquisa origem e destino 1997 - Região Metropolitana de São Paulo. Pesquisa domiciliar e linha de contorno síntese das informações. São Paulo: Metrô, 1999.

METRÔ, Companhia do Metropolitano de São Paulo. Pesquisa origem e destino 2007 - Região Metropolitana de São Paulo. Síntese das Informações -Pesquisa Domiciliar. São Paulo: Metrô, 2008.

METRÔ, Companhia do Metropolitano de São Paulo. Quem somos. On-line. 2017. Disponível em: <http://www.metro.sp.gov.br/metro/institucional/quem-somos/index.aspx>. Acesso em 28 fev. 2017.

ONU, Organização das Nações Unidas. UN-HABITaT. The United Nations perspective on reinventing planning. 2007, p. 15-34

ONU, Organização das Nações Unidas. Rio+20: 0 futuro que queremos. Fatos sobre as cidades. Rio de Janeiro, 2012.

PACHECO, Priscila. O poder das regiões metropolitanas: planejamento urbano além das cidades. The City Cix Brasil, 30 jan. 2017.

PIRES, Yasmin. Pós a distância ganha força no mercado. Especial Folha Dirigida. Suplemento educação. out. 2015.

SANTOS, Claudia Maria Neme dos. Coworking: contribuições de um modelo de consumo colaborativo e da arquitetura corporativa para o gerenciamento das cidades. Revista Nacional de Gerenciamento de Cidades, v. 2, n. 12. 2014.

SAP Consultores Associados. Pesquisa home office Brasil 2015. Campinas/SP: SAP Consultoria em Recursos Humanos, 2015.

SQUAIELLA, Rober ta B. F. O desenvolvimento do ensino superior a distância no Brasil - diretrizes para o projeto dos edifícios e redes espaciais. Dissertação (mestrado em Arquitetura e Urbanismo), Universidade Presbiteriana Mackenzie, 2016.

TREVISAN, Alexandre, et al. Pesquisa home office Brasil 2016. Campinas/SP: SAP Consultoria em Recursos Humanos, 2016. 